\title{
Estabilidade holística, axiológica e ontológica e a escolha de teorias
}

\author{
Holistic, axiologic and ontological stableness \\ and the theory choice
}

Prof. Dr. Marcos Rodrigues da Silva

Departamento de Filosofia da Universidade Estadual de Londrina - UEL

e-mail: mrs.marcos@uel.br

Recebido em:14/04/2021

Aceito em:22/10/2021

\section{RESUMO}

Uma das qualidades atribuídas ao conhecimento científico é a de que esse conhecimento é eliminativo; ou seja: quando se procura explicar um fenômeno, várias alternativas são apresentadas por vários cientistas; a hipótese que explicar o fenômeno de modo superior às hipóteses rivais é considerada tanto a melhor explicação quanto a explicação verdadeira; esta concepção eliminativista possui um pressuposto: as hipóteses rivais compartilham o fenômeno a ser explicado; o objetivo deste artigo é o de questionar esse pressuposto.

Palavras-chave: inferência eliminativa; inferência da melhor explicação; história da ciência

\section{ABSTRACT}

One of the traits assigned to scientific knowledge is that this knowledge is eliminative; that is, when trying to explain a phenomenon, several alternatives are introduced by many scientists; the hypothesis that explaining the phenomenon better than to rival hypotheses is considered both the best explanation and the true explanation; this eliminativist view has one assumption: rival hypotheses share the phenomenon to be explained; the purpose of this article is to question this assumption.

Key-words: eliminative inference; inference to the best explanation; history of science 


\section{Introdução}

Um dos argumentos mais utilizados para explicar filosoficamente a aceitação comunitária de teorias científicas é o argumento da inferência da melhor explicação (doravante mencionado como "IBE"). O argumento se apresenta do seguinte modo: a) um fenômeno precisa ser explicado; b) uma teoria $\mathrm{T}$ explica melhor (e suficientemente bem) o fenômeno do que outras teorias rivais; c) T está de acordo com o conhecimento anterior já aceito pela comunidade científica; logo, d) T é aceita como verdadeira. Este argumento foi proposto por Gilbert Harman em 1965 e posteriormente desenvolvido por vários filósofos da ciência². Seu enunciado original é o seguinte: "Ao inferir a melhor explicação se infere, do fato de que uma certa hipótese explicaria a evidência, a verdade desta hipótese. Em geral várias hipóteses podem explicar a evidência, por isso devemos ser capazes de rejeitar todas hipóteses alternativas antes de estarmos seguros ao fazer a inferência. Portanto se infere, da premissa de que uma dada hipótese forneceria uma 'melhor' explicação para a evidência do que quaisquer outras hipóteses, a conclusão de que esta determinada hipótese é verdadeira" (HARMAN, 2018, p. 326).

No interior da filosofia da ciência, IBE é um argumento que faz parte da escola realista: concepção filosófica que enuncia que as teorias científicas bem-sucedidas instrumentalmente e aceitas pela comunidade científica devem ser aceitas como verdadeiras.

A razão principal para essa aceitação se localiza na premissa (b): é por ela que se determina que uma teoria foi superior a teorias rivais ${ }^{3}$. Observe-se, no entanto, que a competição entre as hipóteses pressupõe como de resto todas competições pressupõem - algo comum; no caso, o que há de comum entre hipóteses rivais seria exatamente o que está enunciado na premissa (a): um fenômeno. Assim, por meio de IBE, há um e mesmo fenômeno que seria compartilhado ao menos por duas hipóteses rivais, gerando-se com isso uma situação de estabilidade ontológica do fenômeno, e com isso temos a seguinte tese: a tese do compartilhamento do fenômeno por hipóteses explicativas rivais.

Assumida essa tese, vejamos um esboço de uma taxonomia de instâncias problemáticas dessa tese. Identifica-se, neste artigo, três situações filosoficamente (e historicamente) problemáticas:

i) compartilhamento, por teorias rivais, de um fenômeno (F) a ser explicado, mas F se relaciona com aspectos científicos diferentes em cada uma das teorias rivais; denominaremos esta situação de diferença holística;

ii) compartilhamento de (F) por teorias rivais, mas essas teorias possuem objetivos científicos diferentes a respeito de (F); denominaremos esta situação de diferença axiológica;

iii) não compartilhamento de fenômenos por teorias rivais, mas existência de uma aparência de compartilhamento em função de as teorias estarem usando a mesma palavra para fenômenos que na verdade são diferentes; denominaremos esta situação de diferença ontológica.

O objetivo deste artigo é o de, por meio de uma apresentação introdutória a cada um destes casos empregando tanto recursos da historiografia da ciência quanto instrumentais de análise filosófica - sugerir que a noção de estabilidade ontológica nem sempre se aplica à história da ciência em casos de competição entre teorias.

1 Das inicias da expressão em inglês Inference to the Best Explanation.

2 Dentre esses estão Stathis Psillos, Alexander Bird, Paul Thagard e Peter Lipton.

3 Essa superioridade é exibida qualquer que seja o critério empregado. Gilbert Harman deixou em aberto o problema de saber quais critérios seriam aplicáveis: "Há, é claro, um problema a respeito de como julgar que uma hipótese é suficientemente melhor que outra hipótese. Tal julgamento, presumivelmente, estará baseado em considerações tais como: qual hipótese é mais simples, qual é mais plausível, qual explica mais, qual é menos ad hoc etc. Eu não desejo negar que há um problema de explicar a natureza exata dessas considerações; porém, não me manifestarei mais sobre este problema" (HARMAN, 2018, p. 326). Paul Thagard, posteriormente, apresentou alguns critérios para preencher o requisito de Harman (THAGARD, 2017). 
1. A premissa (a) de IBE e a diferença holística. Quanto a casos de diferença holística, temos os exemplos da disputa entre Joseph Priestley e Antoine Lavoisier e o da disputa sobre a geração espontânea envolvendo Louis Pasteur e Felix Pouchet. Nos dois casos os rivais compartilhavam o fenômeno e aceitavam-no como necessitando de uma explicação que resolveria um mesmo problema para ambos. Lavoisier e Priestley compartilhavam o fenômeno da combustão; Pasteur e Pouchet compartilhavam o fenômeno do surgimento de matéria orgânica a partir de restos inorgânicos. Eles compartilhavam, portanto, a mesma "classe de fatos" (THAGARD, 2017, p. 148) e desejavam oferecer uma explicação consiliente (que explicaria muitas classes de fatos (THAGARD, 2017, p. 148)) e poderosa em termos de entendimento para os mesmos fenômenos (LIPTON, 2004, p. 59-60).

É importante deixar assentado, aqui, que, nos dois casos, o fenômeno é um e apenas um e, mais importante ainda, que o compartilhamento do fenômeno por hipóteses explicativas rivais é de fato o caso para os envolvidos. Eles estão experienciando os mesmos fenômenos e não se pode, tendo a história dos episódios como referência, argumentar a favor de um relativismo ontológico ou perceptivo. A princípio, então, a premissa (a) de IBE parece estar consolidada e poderíamos assim empregar IBE para mostrar a superioridade de Lavoisier e de Pasteur em relação a seus adversários.

Ocorre, no entanto, que o fenômeno da combustão não está dissociado de outros fenômenos relacionados. A combustão é um processo pneumático e então os tipos de ares nela envolvidos devem ser identificados claramente (THAGARD, 2007); a noção de peso deve estar presente (LEICESTER, 1971, p. 140-141; PARTINGTON, 1937, p. 125); os elementos químicos presentes em um experimento de combustão precisam ser detalhados etc (LAVOISIER, 2007, p. 33-35). Lavoisier, ao contrário de Priestley, trata de todos estes detalhes. Do mesmo modo, no caso de Pasteur, a matéria orgânica resultante de restos inorgânicos talvez apenas aparentemente resulte de fato de restos inorgânicos, pois é possível que haja algo que possua vida (microrganismos) envolvido nesta experimentação (DEBRÉ, 1989, p. 158; PASTEUR, 1861, p. 79); além disso, microrganismos também fazem parte de fenômenos ligados à fermentação (GEISON, 1995, cap. 2; LATOUR, 2001, p. 190). Pasteur, ao contrário de Pouchet, trata de todos estes detalhes. Lavoisier e Pasteur, portanto, ainda que enxerguem os mesmos fenômenos que seus rivais Priestley e Pouchet, os relacionam com outros fenômenos próximos. Desse modo, a premissa (a) não conteria apenas o fenômeno da combustão e o fenômeno da matéria orgânica, mas diversos outros fenômenos, os quais, considerados em sua totalidade nas redes conceituais de Lavoisier e Priestley, indicarão uma nova estrutura comparativa, estrutura essa que não será adequadamente captada por IBE.

É neste sentido que se emprega a expressão diferença holística, visto não se tratar de fenômenos diferentes, mas apenas de um uso dos fenômenos que é diferente em cada abordagem teórica.

Essa diferença holística pode ser compreendida pela noção filosófica de redes conceituais, noção essa associada aos trabalhos de Paul Thagard. Para Thagard (1992), em resumo, fenômenos são conceitualizados e constituem (já conceitualizados) partes de redes conceituais explicativas, redes essas que não podem ser comparadas diretamente ${ }^{4}$ com redes rivais, pois é possível (e os casos de Lavoisier e Pasteur, entre outros, são exemplos disso) que duas redes tratem de um mesmo fenômeno (F), mas uma rede (R1) trate também dos fenômenos A, B e C, e outra rede (R2) trate também dos fenômenos D e E, e (R1) não trate de D e E, e (R2) não trate de A, B e C. Deste modo, (R1) e (R2) só poderiam ser comparadas a respeito de F, mas não a respeito de $\mathrm{A}, \mathrm{B}, \mathrm{C}, \mathrm{D}$ e $\mathrm{E}$.

Em um primeiro momento poderíamos ser inclinados a suspeitar que a premissa de IBE que seria afetada pelas considerações do parágrafo anterior seria a premissa (b) e não a premissa (a). Não se descarta, aqui, que a premissa (b) possa também ser afetada. Porém, considerando o registro histórico que aponta para fatos indiscutíveis a respeito destas polêmicas e disputas científicas, pareceria mais um capricho filosófico do que uma tese histórica sustentar algo como: "as hipóteses sequer chegavam a ser rivais pois lidavam de forma diferente com os fenômenos”. Elas de fato rivalizaram. A questão que aqui se levanta é: em que condições

4 É importante deixar claro que, quando se emprega a expressão "não podem ser comparadas diretamente", isso não significa nenhuma tese a respeito de impossibilidade de escolha racional entre duas redes conceituais não comparáveis diretamente. 
elas rivalizaram? E, na proposta de leitura deste artigo, entende-se que elas de fato rivalizaram, mas de forma localizada, em alguns aspectos, e a disputa não girou em torno apenas em torno de um fenômeno que ambas as redes compartilhavam, mas em torno de vários fenômenos i) interligados em uma rede ii) mas não interligados em outra (e vice-versa).

2. A premissa (a) de IBE e a diferença axiológica. Passemos agora a casos de diferença axiológica (compartilhamento de um fenômeno (F) por teorias rivais, mas essas teorias possuem objetivos científicos diferentes com relação a (F)), para o qual temos o clássico exemplo da construção do modelo da dupla hélice do DNA. Pesquisas sobre o DNA eram realizadas basicamente por três grupos diferentes no início da década de 1950: um no King's College, em Londres, que contava com os pesquisadores Maurice Wilkins e Rosalind Franklin (WILKINS, 2003); um grupo no Instituto Cavendish, em Cambridge (Inglaterra), que contava com James Watson e Francis Crick (WATSON, 1997); e por fim o grupo liderado por Linus Pauling, no Caltech, na Califórnia (SAPP, 2003). O fenômeno a ser explicado estava materializado em chapas de raio-X do DNA (obtidas por meio da técnica de difração de raio-x), e era compartilhado por todos os três grupos. Não obstante este consenso evidencial, os objetivos científicos associados ao DNA eram completamente diferentes (OLBY, 1974, p. 396-397). Para o grupo do King's College, o interesse era determinar a estrutura do DNA (SAYRE, 1975; MADDOX, 2002); o objetivo de Linus Pauling era mais ou menos o mesmo, com a diferença de uma generalização metodológica: Pauling estava em busca de estruturas de várias moléculas (e já havia descoberto a estrutura de uma proteína, a queratina) (MORANGE, 1998, p. 109); já para Watson e Crick, o objetivo era determinar a estrutura do DNA desde que essa estrutura fosse útil para se compreender sua função genética (WATSON, 1997, p. 147, p. 154; OLBY 1974, pp. 396-397; p. 416; JUDSON, 1979, p. 177; CREAGER e MORGAN, 2008, p. 270; MORANGE, 1998, p. 115-116; WATSON e CRICK, 1953a, p. 737; WATSON e CRICK, 1953b, p. 965). Resumindo, percebemos então duas situações axiológicas: i) os três grupos compartilham um objetivo comum: determinar a estrutura da molécula; ii) apenas um grupo (de Watson e Crick) possui um objetivo adicional: obter a estrutura do DNA para compreender sua função genética.

Watson e Crick, embora fizessem uso de vários experimentos produzidos por outros cientistas, não faziam trabalhos empíricos. Já Rosalind Franklin produzia dados empíricos da molécula de DNA, e queria elucidar apenas a estrutura da molécula. Em maio de 1952 Rosalind Franklin produziu dados que apontavam claramente uma estrutura helicoidal. Não obstante, ela não propôs nenhuma estrutura. Watson e Crick posteriormente (em fevereiro de 1953) tiveram acesso a esses dados e com base neles e diversas outras informações científicas, propuseram o conhecido modelo da dupla hélice do DNA.

Ora, considerando a premissa (a) de IBE, torna-se difícil compreender por que Rosalind Franklin não propôs uma estrutura do DNA, a menos que se assuma alguma limitação científica de Rosalind Franklin visto não ter ela proposto uma estrutura a partir dos mesmos dados disponíveis a Watson e Crick; mas essa limitação não é referendada pela história da ciência e Rosalind Franklin é considerada uma das maiores cristalógrafas de raiox-X. Resta uma outra hipótese, incompatível com a premissa (a) de IBE.

Watson e Crick (mas não Rosalind Franklin) procuravam elucidar a estrutura do DNA a fim de compreenderem algo sobre a função genética do DNA; tendo esse objetivo, mobilizaram diversos outros elementos científicos (tais como a orientação geral de Erwin Schrödinger de que um agente hereditário precisa ter estabilidade, a importância do DNA na transformação bacteriana apontada por Oswald Avery, as Regras de Chargaff etc). Assim, o fato de que o fenômeno era compartilhado por Watson/Crick e Rosalind Franklin não implicava, dados os diferentes objetivos de investigação, que esse fenômeno seria tratado do mesmo modo.

Novamente é importante esclarecer que não estamos diante de qualquer forma de relativismo ontológico: o fenômeno é um e apenas um. No entanto, o tratamento a esse fenômeno foi diferente por parte de Watson e Crick tendo em vista que seu objetivo era também diferente. E, assim como no primeiro caso, rejeita-se aqui a ideia de que não houve competição; no entanto, a competição não era um jogo com regras iguais, dados que os objetivos de pesquisa eram bastante diferentes em função da diferença axiológica quanto ao tratamento do fenômeno. 
Para compreender este aspecto e com isso se compreender que a crítica de fato se dirige à premissa (a), busca-se apoio na chamada abordagem historiográfica, de Thomas Kuhn.

De acordo com Kuhn (1970), existem duas grandes unidades que compõem as disciplinas científicas: paradigmas e teorias. Em termos relativamente não-técnicos, paradigmas são amplas orientações científicas que fornecem aos cientistas uma igualmente vasta perspectiva da realidade; esta perspectiva, ainda em termos ligeiramente não-técnicos, faz com que os cientistas investiguem os fenômenos apontados pelo paradigma como importantes, e essas investigações terão como resultado final teorias específicas. Deste modo, paradigmas são orientações gerais para pesquisas específicas cujos resultados serão expressos na forma de teorias igualmente específicas.

Com base na distinção entre paradigmas e teorias, podemos agora esclarecer a diferença axiológica entre, por um lado, Watson e Crick, e, por outro, o grupo do King's College e Linus Pauling. Para estes últimos, elucidar a estrutura molecular do DNA ofereceria como resultado final uma teoria específica sobre o DNA e suas propriedades físico-químicas. Já para Watson e Crick, elucidar a estrutura química do DNA significava oferecer aos biólogos um ponto de partida geral para a compreensão de fenômenos genéticos à luz da nascente genética molecular (Ridley 2006, p. 197) - ou, em outras palavras, construir um paradigma a partir do qual a pesquisa se desenvolveria. E, no que diz respeito a IBE, pode-se concluir do episódio histórico que a dupla hélice do DNA não era a melhor explicação para os fenômenos observados por meio da difração de raio-X; ou, caso seja assim considerada, ela também era muito mais do que isso, de modo que este acréscimo não consegue ser capturado por IBE.

3. A premissa (a) de IBE e a diferença ontológica. Passamos agora a casos de diferença ontológica (onde não há compartilhamento de fenômenos por teorias rivais, mas existência de uma aparência de compartilhamento em função de as teorias estarem usando a mesma palavra para fenômenos diferentes), para o qual temos o exemplo do fenômeno de adaptação para os teólogos e historiadores naturais, e posteriormente para Charles Darwin.

É argumentado por alguns historiadores e filósofos da biologia que Darwin tinha como um de seus objetivos solucionar o problema da adaptação (GOULD, 2002, p. 156; BLANC, 1994, p. 48; AYALA, 2004, p. 55-56), e o fenômeno denominado de "adaptação" seria o mesmo fenômeno denominado também de "adaptação" pelos teólogos e historiadores naturais que antecederam Darwin. Assim, Darwin estaria tentando explicar o mesmo fenômeno que os teólogos e historiadores naturais.

Porém, de acordo com o historiador Gustavo Caponi, Darwin não partilhava com seus predecessores o conceito "adaptação"; ou seja: embora a palavra "adaptação" tivesse sido empregada por todos, não haveria aqui uma identidade semântica para a palavra. De acordo com Caponi, o tema central em torno do qual gira a discussão anterior a Darwin é o da economia natural: por conta desta economia natural, um organismo possui um papel a cumprir e não precisa conquistar e defender um lugar a fim de sobreviver. Na concepção pré-darwinista, por meio do conceito de economia natural pressupunha-se que todos os organismos vivem para os outros e não para si mesmos, gerando uma concepção mutualista, na qual a razão de ser de um organismo é seu papel para a manutenção de uma ordem natural. Ainda que não de forma explícita, o programa de pesquisa da história natural impunha um compromisso teórico com o tema da economia natural, compromisso este assumido por Cuvier, Bufon e Lamarck, para citar os grandes nomes deste programa de investigação. Neste caso, a pergunta darwinista - "como os seres vivos conquistam e conservam seu espaço na natureza?" - era desnecessária e sem contexto teórico. Porém modifiquemos o foco teórico: um naturalista deseja explicar a formação da árvore da vida, e explicar por que todas as espécies descendem de um ancestral comum. A explicação para isto é a seleção natural. Mas sobre qual fato atua a seleção natural? Responde Caponi (2011, p. 53-54): a seleção natural não se limita a operar sobre a correlação interna das partes dos organismos e sobre correlações entre órgãos e meio externo (pontos para os quais já haviam chamado a atenção Cuvier e Paley). Ela precisa ir além. E precisa ir além por conta, agora sim, de um fato para Darwin: ela precisa operar um ajuste entre os seres vivos e um ambiente muito mais minucioso do que 
o descrito pelos teólogos e historiadores naturais. Assim, temos aqui um fato "novo" (gerado pela teoria, por assim dizer): um ambiente hostil.

Estamos então diante da novidade teórica revolucionária: torna-se necessário, pela imposição da teoria darwinista, estudar detalhadamente a história dos seres vivos (CAPONI, 2011, p. 64). Com isso surge um novo questionário, ao invés de uma nova resposta a velhas perguntas (CAPONI, 2011, p. 83). Para Caponi, a seleção natural, enquanto solução para o problema da árvore da vida, gerava uma nova dificuldade explicativa posterior, dado que aparecia como uma consequência da própria teoria da seleção natural (2011, p. 46), e por isso a adaptação seria não um fato estabelecido, mas uma dificuldade gerada pela teoria.

Torna-se óbvio então que o termo "adaptação" possui um significado para a teologia e história naturais e outro completamente diferente para Darwin. Evidentemente, eles não estão completamente dissociados; porém, no interior de diferentes esquemas conceituais, eles possuem significados muito diferentes.

É importante, neste terceiro caso, recuperar uma das teses gerais deste artigo; pois, embora agora não estejamos mais (como nos dois primeiros casos) tratando do mesmo fenômeno, ainda podemos comparar os esquemas rivais; contudo, tal comparação (como nos dois primeiros casos) dificilmente pode ser compreendida por meio de IBE.

Para compreender casos de diferença ontológica e com isso se compreender que a crítica se localiza na premissa (a), emprega-se o conceito de interpretação natural de Paul Feyerabend.

Originalmente, Feyerabend acionou este conceito para compreender o modo como Galileu estruturou sua defesa do sistema heliocêntrico de Copérnico. Testes experimentais produzidos por Galileu não conseguiram remover algumas dificuldades do sistema de Copérnico. Uma destas dificuldades aparecia no chamado "argumento da torre": se a Terra estivesse se mexendo, quando uma pedra fosse jogada do alto de uma torre ela não cairia ao pé da torre, mas a alguns metros de distância (no chão) da torre (FEYERABEND, 1993, p. 55-56). De acordo com Feyerabend, Galileu aceitou a natureza sensorial do argumento da torre; ele seria, ademais, uma "interpretação natural", uma interpretação intuitiva e em acordo com nossos sentidos (Feyerabend, 1993, p. 57-58). Neste sentido, a interpretação natural parece refutar a teoria de Copérnico. Mas, argumenta Feyerabend, pode-se tentar outro caminho: talvez a teoria de Copérnico possa ser desenvolvida, se as interpretações naturais forem "aprimoradas" (FEYERABEND, 1993, p. 60); mas como aprimorá-las no interior de um programa de pesquisa vigente (o sistema geocêntrico de Ptolomeu e a física de Aristóteles)? Neste caso, para Feyerabend, deve-se criar uma "medida externa de comparação" (FEYERABEND, 1993, p. 61). No caso, Galileu coloca como medida externa de comparação o próprio programa de pesquisa de Copérnico. Essa medida externa de comparação irá ambientar os fatos que contradizem a teoria que está em desacordo com a interpretação natural do programa de pesquisa vigente, de modo que a teoria ainda não estabelecida (a de Copérnico) possa se desenvolver (FEYERABEND, 1993, p. 61-62). Fazendo isso, Galileu não contesta o argumento da Torre, mas mostra que, supondo que a Terra se mova, isso não perturba a sensorialidade daquele que vê a pedra cair ao pé da torre. A explicação de Galileu (FEYERABEND, 1993, p. 67-68) é a de que a Terra está se mexendo e por isso a torre também; assim, a pedra continua a cair ao pé da torre, mesmo pressupondo o movimento da Terra.

Do mesmo modo, Darwin não contesta que os organismos estejam "adaptados" a seu ambiente, conforme sinalizado pelos teólogos e historiadores naturais. No entanto, o fato da adaptação apontado pelos teólogos e historiadores naturais é diferente do fato adaptativo apontado por Darwin, embora a percepção científica seja a mesma; o que altera é que, no primeiro caso, um organismo está adaptado por conta da economia natural e por conta da correlação entre suas partes, ao passo que, para Darwin, esta correlação não é suficiente, uma vez que a realidade é hostil e coloca exigências que vão além do que é previsto pela noção de economia natural.

Assim, o que se pode concluir é que as duas tradições estão empregando a mesma palavra ("adaptação") mas se referindo a fenômenos diferentes, e, ao usar a mesma palavra, passa-se a impressão de estarem tratando do mesmo fenômeno e, portanto, a impressão de estarem competindo na mesma plataforma. 


\section{Consideração finais}

IBE capta, apropriadamente, a existência de disputas científicas e de comparação entre alternativas rivais. O que uma análise aprofundada da premissa (a) de IBE procura mostrar é que essa comparação, sem prejuízo para a questão da racionalidade científica, não ocorre sempre nos moldes indicados por IBE.

É importante ressaltar aqui a expressão "racionalidade científica". É comum, no interior da concepção tradicional filosófica sobre ciência (da qual o realismo científico faz parte), alegar (como fazem LEPLIN, 1997, p. 4; NIINILUOTO, 1991, p. 152; NELSON, 1994, p. 541; SIEGEL, 1986, p. 241; KUKLA, 2000, p. 9), que a ênfase em diferenças perceptivas conduz à quebra da confiabilidade atribuída à ciência.

Contudo, as críticas aqui apresentadas a IBE não se inserem em um quadro de crítica à racionalidade científica, senão que ao modo como IBE apresenta a situação comparativa das alternativas rivais. A percepção dos fenômenos não é por si só relativa (ou ontologicamente relativa); ela é sim relativa quando considerados os quadros conceituais, os paradigmas e os problemas de cada tradição que lida com o fenômeno (que continua sendo um e apenas um) (cf. LEWENS, 2005, p. 596; BOWLER, 1989, p. 94-95; BARNES, BLOOR e HENRY, 1996, p. 25; HANSON, 1958, cap. 1). E esse tipo de relatividade perceptiva não implica nenhum dano à noção de "racionalidade científica".

\section{Referências Bibliográficas}

AYALA, F. “La selección natural como explicación causal em lá evolución biológica”, Historia y explicación em biologia. Cidade do México: Ediciones Científicas Universitarias, 1998.

BARNES, B, BLOOR, D., HENRY, J. Scientific Knowledge: A Sociological Analisys. London: Athlone, 1996.

BLANC, M. Os Herdeiros de Darwin. São Paulo: Scritta, 1994.

BOWLER, P. The Mendelian Revolution. Baltimore: Johns Hopkins University Press, 1989.

CAPONI, G. La Segunda Agenda Darwiniana. Cidade do México: Centro de Estudios Filosóficos, Políticos y Sociales Vicente Lombardo Toledano, 2011.

CREAGER, A., MORGAN, G. After the Double Helix. Isis, 99, 2008.

DEBRÉ, P. Louis Pasteur. (Translation by Elborg Forster.) Baltimore: Johns Hopkins University Press, 1989.

FEYERABEND, P. Against Method (3. ed.). Londres: Verso, 1993.

GEISON, G. The Private Science of Louis Pasteur. Princeton: Princeton University Press, 1995.

GOULD, S. The Structure of Evolutionary Theory. Cambridge: Harvard University Press, 2002.

HANSON, N. Patterns of Discovery. Cambridge: Cambridge University Press, 1958.

HARMAN, G. Inferência da Melhor Explicação, Dissertatio, 47, 2018.

JUDSON, H. The Eight Day of Creation. London: Jonathan Cape, 1979.

KUKLA, A. Social Constructivism and the Philosophy of Science. London: Routledge, 2000.

KUHN, T. The Structure of Scientific Revolutions. Chicago: Chicago Press, 1970.

LATOUR, B. A Esperança de Pandora. Bauru: Edusc, 2001.

LAVOISIER, A. Tratado Elementar de Química. São Paulo: Madras, 2007.

LEICESTER, H. The Historical Background of Chemistry. New York: Dover, 1971.

LEPLIN, J. A Novel Defense of Scientific Realism. Oxford: Oxford University Press, 1997.

LEWENS, T. Realism and the Strong Program, British Journal for the Philosophy of Science, 56, 2005.

LIPTON, P. Inference to the Best Explanation. (2. ed.) London: Routledge, 2004.

MADDOX, B. Rosalind Franklin: The Dark Lady of DNA. New York: Harper Colins, 2002. 
MORANGE, M. A History of Molecular Biology. (Translation by Matthew Cobb). Cambridge: Harvard University Press, 1998.

NELSON, A. How Could Scientific Facts be Socially Constructed?, Studies in History and Philosophy of Science, v. 25, n. 4, 1994.

NIINILUOTO, I. Realism, Relativism, and Constructivism, Synthese, 89, 1991.

OLBY, R. The Path to the Double Helix. London: MacMillan, 1974.

PARTINGTON, J.R. A Short History of Chemistry. New York: Dover, 1937.

PASTEUR, L. “Mémoire Sur les corpuscles organisés qui existent dans l’atmosphère: Examen de la doctrine des générations spontanées”, 1861.

RIDLEY, M. Francis Crick: discoverer of the genetic code. New York: Harper Colins, 2006.

SAPP, J. Genesis: the evolution of biology. Oxford: Oxford University Press, 2003.

SAYRE, A. Rosalind Franklin and DNA. New York: W.W. Norton \& Company, 1975.

SIEGEL, H. Relativism, Truth, and Incoherence, Synthese, 68, 1986.

THAGARD, P. Conceptual revolutions. Princeton: Princeton University Press, 1992.

THAGARD, P. A Estrutura Conceitual da Revolução Química, Princípios, v. 14, n. 22, 2007.

THAGARD, P. A Melhor Explicação: Critérios para a Escolha de Teorias, Cognitio, v. 18, n. 1, 2017.

WATSON, J, CRICK, F. A Structure for Deoxyribose Nucleic Acid, Nature 171, 1953a.

WATSON, J, CRICK, F. Genetical Implications of the Structure of Deoxyribose Acid, Nature 171, $1953 \mathrm{~b}$.

WATSON, J. The Double Helix. London: Weidenfeld \& Nicolson, 1997.

WILKINS, M. The Third Man of the Double Helix. Oxford: Oxford University Press, 2003. 